\title{
Analisis Pengaruh Kepemimpinan, Lingkungan Kerja Dan Tekanan Pekerjaan Terhadap Kinerja Karyawan PT. Menara Hutama Cibitung
}

\author{
Agrasadya, S. E., M. M \\ Dosen Fakultas Eknnomi Universitas Pamulang \\ Email : dosen01866@unpam.ac.id
}

\begin{abstract}
ABSTRAK
Penelitian ini bertujuan untuk mengetahui pengaruh Variabel kepemimpinan, lingkungan kerja dan tekanan pekerjaan secara simultan terhadap kinerja karyawan PT. Menara Hutama Cibitung. Data yang dikumpulkan berasal dari 88 karyawan perusahaan tersebut. Jumlah tersebut sampel yang diambil secara jenuh.

Data tersebut kemudian dianalisis dengan menggunakan regresi dan pengujian statistik dengan uji $\mathrm{F}$ dan uji t. Berdasarkan pada analisis data diketahui bahwa (1) variabel kepemimpinan berpengaruh terhadap kinerja karyawan sebesar 0,340. Artinya variabel kepemimpinan secara parsial berpengaruh terhadap kinerja karyawan sebesar 34\%. (2) Variabel lingkungan kerja berpengaruh terhadap kinerja karyawan sebesar 0,838. Artinya variabel lingkungan kerja berpengaruh secara signifikan terhadap kinerja karyawan sebesar 83,8\%. (3) Variabel tekanan pekerjaan berpengaruh terhadap kinerja karyawan sebesar 0,842. Artinya variabel tekanan pekerjaan berpengaruh secara signifikan terhadap kinerja karyawan sebesar 84,2\%. (4) Variabel kepemimpinan, lingkungan dan tekanan pekerjaan secara simultan berpengaruh terhadap kinerja karyawan sebesar 0,882. Artinya bahwa kepemimpinan, lingkungan dan tekanan pekerjaan berpengaruh secara simultan terhadap kinerja karyawan PT. Menara Hutama Cibitung sebesar 88,2\% sedangkan sisanya 12,8\% dipengaruhi oleh faktor lain yang tidak termasuk dalam lingkup penelitian ini.

Dari hasil analisis data dapat disimpulkan bahwa kepemimpinan, lingkungan kerja dan tekanan pekerjaan secara parsial maupun simultan berpengaruh signifikan terhadap kinerja.
\end{abstract}

\section{Kata Kunci: Kepemimpinan, Lingkungan Kerja, Tekanan Pekerjaan, Kinerja Karyawan}




\section{PENDAHULUAN}

\section{A. Latar Belakang}

Dalam melaksanakan tugasnya dilapangan karyawan membutuhkan sikap kepemimpinan dari dari para direktur atau kepala bagian dengan baik. Kepemimpinan dibutuhkan untuk dapat mengarahkan dan mempengaruhi bawahan agar dapat melaksanakan kegiatan sesuai dengan tujuan organisasi.

Kepemimpinan dibutuhkan tidak saja untuk dapat mengarahkan dan mempengaruhi bawahan agar melaksanakan tugasnya tetapi juga dalam rangka membangkitkan semangat kerja karyawan. Menurut Hasibuan (2003:170) Kepemimpinan adalah cara seorang pemimpin mempengaruhi perilaku bawahan agar mau bekerja sama dan bekerja secara efektif dan efisien untuk mencapai tujuan organisasi. Kepemimpinan tersebut harus mampu mengarahkan staf agar dapat melakukan kegiatan seuai tujuan yang diharapkan.

Selain faktor kepemimpinan, lingkungan kerja turut memberikan andil bagi pencapaian kinerja karyawan yang baik. Menurut Alex S.Nitisemito (1992), lingkungan kerja adalah kondisi internal maupun eksternal yang dapat mempengaruhi semangat kerja sehingga dengan demikian pekerjaan dapat diharapkan selesai lebih cepat dan baik. Semakin baik kondisi lingkungan maka kinerja yang dihasilkan juga semakin besar.

Faktor lain yang perlu diperhatikan dalam meningkatkan kinerja karyawan adalah tekanan pekerjaan. Tekanan pekerjaan merupakan kondisi dari organisasi yang menekan karyawan agar dapat bekerja dengan baik. Tekanan pekerjaan yang meningkat justru akan meningkatkan kinerja. Namun tekanan kerja yang terus meningkat pada titik tertentu tidak akan menghasilkan kinerja karyawan yang baik tetapi justru akan menghasilkan kinerja karyawan yang tidak sehat.
Berdasarkan pada hal tersebut peneliti tertarik untuk dapat melakukan penelitian dengan judul Pengaruh Kepemimpinan, lingkungan kerja dan tekanan pekerjaan terhadap kinerja karyawan PT. Menara Hutama Cibitung.

\section{B. Perumusan Masalah}

1. Bagaimana pengaruh Kepemimpinan, lingkungan kerja dan tekanan pekerjaan terhadap kinerja karyawan PT. Menara Hutama secara simultan

2. Bagaimana pengaruh kepemimpinan secara parsial terhadap kinerja karyawan PT. Menara Hutama

3. Bagaimana pengaruh lingkungan kerja secara parsial terhadap kinerja karyawan PT. Menara Hutama

4. Bagaimana pengaruh tekanan pekerjaan secara parsial terhadap kinerja karyawan PT. Menara Hutama

\section{Tujuan Penelitian}

1. Untuk mengetahui pengaruh kepemimpinan, lingkungan kerja dan tekanan pekerjaan terhadap kinerja karyawan PT. Menara Hutama secara simultan

2. Untuk mengetahui pengaruh kepemimpinan secara parsial terhadap kinerja karyawan PT. Menara Hutama secara parsial

3. Untuk mengetahui pengaruh lingkungan kerja terhadap kinerja karyawan PT. Menara Hutama secara parsial

4. Untuk mengetahui pengaruh tekanan kerja terhadap kinerja karyawan PT. Menara Hutama secara parsial

II. Tinjauan Pustaka

A. Pengertian Manajemen Sumber Daya Manusia 
Manajemen sumber daya manusia menurut Sofyandi (2009:6) didefinisikan sebagai suatu strategi dalam menerapkan fungsi-fungsi manajemen yaitu planning, organizing, leading dan controlling, dalam setiap aktifitas/fungsi operasional SDM mulai dari proses penarikan. Seleksi, pelatihan dan pengembangan, penepatan yang meliputi promosi, demosi dan transfer, penilaian kinerja, pemberian kompensasi, hubungan industrial, hingga pemutusan hubungan kerja, yang di tujukan bagi peningkatan kontribusi produktif dari SDM organisasi terhadap pencapaian tujuan organisasi secara lebih efektif dan efisien.

\section{B. Pengertian Kepemimpinan}

Fiedler dalam Hanafi (2002) menjelaskan bahwa kepemimpinan adalah kemampuan memberikan pengarahan dan koordinasi kepada bawahan dalam mencapai tujuan organisasi, serta kesediaan untuk menjadi penanggung jawab utama dari kegiatan kelompok yang dipimpinnya.

$$
\text { Kepemimpinan sebagai }
$$

kemampuan untuk mempengaruhi kelompok menuju pencapaian sasaran. Sumber dari pengaruh ini bersifat formal, seperti yang disajikan oleh kepemilikan peringkat manajerial dalam organisasi karena posisi manajemen muncul bersamaan sejumlah tingkat wewenang yang dirancang secara formal, seseorang dapat menjalankan peran kepemimpinan semata-mata karena dalam kedudukannya dalam organisasi itu.

\section{Pengertian Lingkungan Kerja}

Menurut Sedarmayanti (2003:12) kondisi lingkungan kerja dikatakan baik atau sesuai apabila manusia dapat melaksanakan kegiatan secara optimal, sehat, aman, dan nyaman. Kesesuaian lingkungan kerja dapat dilihat akibatnya dalam jangka waktu yang lama lebih jauh lagi lingkungan-lingkungan kerja yang kurang baik dapat menuntut tenaga kerja dan waktu yang lebih banyak dan tidak mendukung diperolehnya rancangan sistem kerja yang efisien.

\section{Pengertian Tekanan Pekerjaan}

Secara formal, stress adalah "suatu respon yang adaptif, dihubungkan oleh karakteristik dan/ atau proses psikologis individu, yang merupakan suatu konsekuensi dari setiap tindakan eksternal,situasi, atau peristiwa yang menempatkan tuntutan psikologis dan atau fisik khusus pada seseorang.

Stres kerja adalah stres yang dikarenakan adanya ketidakseimbangan antara karakteristik kepribadian karyawan dengan karakteristik aspek-aspek pekerjaannya dan dapat terjadi pada semua kondisi pekerjaan.

\section{E. Pengertian Kinerja}

Gibson (1987) menyatakan ada 3 faktor yang berpengaruh terhadap kinerja. Faktor pertama adalah faktor individu, seperti kemampuan, keterampilan, latar belakang keluarga, pengalaman kerja, tingkat sosial dan demografi seseorang.Kedua adalah faktor psikologis, seperti persepsi, peran, kepribadian, motivasi dan kepuasan kerja. Faktor ketiga adalah faktor organisasi, seperti struktur organisasi, desain pekerjaan, kepemimpinan dan sistem penghargaan. Dari pernyataan Gibson tersebut menjelaskan bahwa faktor psikologis kepuasan kerja dan faktor organisasi seperti motivasi, akan berpengaruh terhadap kinerja.

\section{Metode Penelitian}

Sampel adalah penarik sebagian dari populasi untuk mewakili seluruh populasi, (Winarno Surakhmad, 1990). Sampel yang digunakan oleh penulis dalam penelitian ini adalah karyawan PT. Menara Hutama di Cibitung.

Jumlah seluruh karyawan sebanyak 88 orang. Jumlah tersebut adalah jumlah keseluruhan karyawan pada perusahaan. Teknik pengambilan sampel ini disebut 
juga dengan metode pengambilan sampel jenuh. Dalam metode pengambilan sampel ini populasi seluruhnya dilibatkan dalam pengambilan sampel.

\section{A. Uji Asumsi Penyimpangan Klasik}

Tahapan pengolahan data dalam penelitian ini adalah uji asumsi klasik dengan regresi seperti uji linieritas, uji heteroskedasitas, uji normalitas, uji multikolinearitas dan autokorelasi serta pencarian statistik deskriptif yaitu nilai rata-rata, median modus, standar deviasi dan range (jangkauan).

\section{Linieritas}

Pengujian ini dilakukan untuk mengetahui apakah data-data yang digunakan linear (searah). Untuk melihat linieritas model regresi, dengan cara : membandingkan probability $\mathrm{F}>\alpha=0,05$ atau $5 \%$.

\section{Heteroskedasitas}

Untuk melihat apakah model regresi linier terdapat bias atau tidak, melalui parameter koefisien Spearman yaitu dengan membandingkan to dengan $\alpha=5 \%$ dengan rumus sebagai berikut :

$t_{0}=\frac{r_{s} \sqrt{n-2}}{\sqrt{1-r s^{2}}}$

- Jika to $>\alpha=5 \%$, maka pada model regresi berganda terdapat hubungan linier antara variabel independent dengan variabel dependen, yang berarti tidak terdapat heteroskedasitas pada models yang terbentuk.

- Jika to $<\alpha=5 \%$, maka pada model regresi berganda tidak terdapat hubungan linier antara variabel independent dengan variabel dependen, yang berarti terdapat heteroskedasitas pada models yang terbentuk.

\section{Normalitas}

Uji normalitas untuk mengetahui apakah model tersebut berasal dari distribusi normal atau tidak, melalui parameter Kolmogorov Smirnov Test dilakukan dengan cara : membandingkan nilai Asymp. Sig dengan taraf signifikansi atau $\alpha=$ $5 \%$

- Jika nilai Asymp. Sig $<\alpha=5 \%$, berarti pada model berasal dari data yang berdistribusi tidak normal .

- Jika nilai Asymp. Sig $>\alpha=5 \%$, berarti pada model berasal dari data yang berdistribusi normal.

\section{Uji Autokorelasi}

- Melalui parameter grafik, gambaran plot Residual atau Deviasi urut waktu adalah apabila beberapa urutan waktu residunya positif dan beberapa urutan waktu yang lain residunya negatif, maka model yang terbentuk autokorelasi.

- Melalui Uji Durbin Watson

$$
D W=\frac{\sum\left(1_{n}-1_{n-1}\right)}{\sum 1_{n}^{2}}
$$

Untuk mendeteksi terjadinya autokorelasi dalam penelitian ini maka digunakan uji DW dengan melihat koefisien korelasi DW test (Algifari, 1997).

Tabel 1.2. Koefisien korelasi DW

\begin{tabular}{|c|c|}
\hline $\begin{array}{c}\text { TINGKAT } \\
\text { AUTOKORELASI } \\
\text { (DURBIN WATSON) } \\
\text { DW }\end{array}$ & Kesimpulan \\
\hline Kurang dari 1,10 & Ada autokorelasi \\
\hline $1,10-1,54$ & $\begin{array}{c}\text { Tidak ada } \\
\text { kesimpulan }\end{array}$ \\
\hline $1,55-2,46$ & $\begin{array}{c}\text { Tidak ada } \\
\text { autokorelasi }\end{array}$ \\
\hline $2,47-2,90$ & $\begin{array}{c}\text { Tidak ada } \\
\text { kesimpulan }\end{array}$ \\
\hline Lebih dari 2,91 & $\begin{array}{c}\text { Ada } \\
\text { autokorelasi }\end{array}$ \\
\hline
\end{tabular}

\section{B. Rancangan Pengujian Hipotesis}

Dalam upaya menganalisis masalah yang diketengahkan dan menguji ke - 4 (empat) hipotesis, pada umumnya akan 
dianalisis melalui pendekatan-pendekatan Kualitatif Naratif dan Analitis. Namun, untuk menganalisis dan menguji hubungan dan pengaruh antara independent variabel atau exogen terhadap endogen variabel atau dependent variabel.

Kemudian untuk mengamati masing-masing signifikansi model, akan dilakukan melalui penduga uji $\mathrm{t}$, dan $\mathrm{F}$ hitung. Permodelan-permodelan prediksi yang digunakan untuk menjawab permasalahan-permasalahan dan membuktikan hipotesis yang diajukan, dimana variabel yang diteliti masingmasing diberi notasi sebagai berikut :

$$
\begin{aligned}
& \hat{Y} \quad=\text { Kinerja karyawan } \\
& \mathrm{X}_{1} \quad=\text { kepemimpinan } \\
& \mathrm{X}_{2} \quad=\text { lingkungan kerja } \\
& \mathrm{X}_{3}=\text { Tekanan Pekerjaan } \\
& \text { Bentuk fungsi secara umum }
\end{aligned}
$$
dapat dinyatakan sebagai berikut :

$\mathrm{Y}=f\left(\mathrm{X}_{1}, \mathrm{X}_{2}, \mathrm{X}_{3}\right)$ atau dalam fungsi matematis:

\section{Uji Kualitas Data}

Kusioner yang akan digunakan pada penelitian, untuk menghasilkan instrumen yang valid dan reliabel terlebih dahulu diuji dengan uji validitas dan reliabilitas instrumen. Menurut Sugiyono (2007 : 219) "Validitas adalah keadaan yang menggambarkan tingkat instrumen yang bersangkutan mampu mengukur apa yang seharusnya di ukur". Sedangkan reliabilitas adalah suatu nilai yang menunjukan konsistensi suatu alat pengukur di dalam mengukur gejala yang sama (Riduwan, 2003 : 86). Dengan menggunakan instrumen yang valid dan reliabel, maka diharapkan hasil penelitian akan menjadi valid (syah) dan reliabel (dapat dipercaya).

1. Uji Validitas Data

Pengujian validitas instrumen menggunakan analisis item, yaitu mengkolerasikan skor tiap butir dengan skor total yang merupakan jumlah tiap skor butir. Koefisien korelasi yang digunakan adalah koefisien korelasi Product Moment.
Rumusnya adalah sebagai berikut :

$$
r=\frac{n \cdot\left(\sum \cdot x y\right)-\left(\sum \cdot x\right) \cdot\left(\sum \cdot y\right)}{\sqrt{\left\{n \cdot \sum \cdot x^{2}-\left(\sum \cdot x\right)^{2}\right\} \cdot\left\{n \cdot \sum \cdot y^{2}-\left(\sum \cdot y\right)^{2}\right\}}}
$$

(Sumber : Sugiyono $2004: 125$ )

Dimana :

$\mathrm{r}=$ Koefisien korelasi

$\mathrm{n}=$ Jumlah sampel

$\mathrm{x}=$ Nilai skor satu item pertanyaan

seluruh responden

$\mathrm{y}=$ Total skor item pertanyaan tiap responden

2. Uji Reliabilitas Data

Mencari reliabilitas instrumen

yang skornya bukan 0-1, tetapi merupakan rentangan antara beberapa nilai, misalnya $0-10$ atau $0-100$ atau bentuk skala 1-3, 1-5, atau 1-7, dan seterusnya dapat menggunakan koefesien alpha $(\alpha)$ dari Cronbach.

Rumusnya adalah seperti berikut.

$$
\mathrm{r}_{11}=\left(\frac{\mathrm{k}}{\mathrm{k}-1}\right) \cdot\left(1-\frac{\sum \sigma_{\mathrm{b}}^{2}}{\sigma_{\mathrm{t}}^{2}}\right)
$$

(Sumber : Husein Umar, 2003 : 96)

Di mana :

$\mathrm{r}_{11}=$ Reliabilitas instrumen

$\mathrm{k}$ = Banyaknya butir pertanyaan

$\sigma_{\mathrm{t}}^{2}=$ Varian total

$\Sigma \sigma_{\mathrm{b}}{ }^{2} \quad$ Jumlah varian butir

Setelah melakukan uji reliabilitas dan validitas terhadap butir-butir kuesioner, langkah selanjutnya adalah merubah data / peningkatan data ordinal (Skala Likert) ke data interval melalui Methode Of Successive Interval (MSI). Caranya adalah melalui langkah-langkah berikut :

a. Mengadakan tabulasi data kuesioner dari item jawaban yang menggunakan skala likerts (likert scale).

b. Mengadakan perengkingan dari setiap item jawaban

c. Menghitung nilai proporsi dan proporsi komulatifnya

d. Menghitung nilai $\mathrm{Z}$ tabel distribusi normal untuk setiap proporsi komulatifnya. Untuk 
data $\mathrm{n}>30$ dianggap mendekati luas daerah dibawah kurva normal.

e. Menghitung nilai densitas/kerapatan untuk setiap proporsi komulatif dengan memasukkan nilai $\mathrm{Z}$ pada tabel ordinal distribusi normal baku.

f. Menghitung SV (Scale Value) melalui model:

$S V=\frac{\text { Density at lower }- \text { density at upperlimit }}{\text { Area under upper limit }- \text { area under lower limit }}$

g. Dengan demikian, SV (Scale Value) yang terkecil (negatif terbesar) diubah menjadi satu.

Uji signifikasi (pengaruh nyata) dari variabel bebas (X) terhadap variabel terikat (Y) baik secara bersama-sama (serentak) maupun sendiri-sendiri (parsial) akan dilakukan dengan uji statistik $\mathrm{F}(\mathrm{F}-$ test) dan uji statistik $\mathrm{t}$ (t-test). Pengujian terhadap hipotesis yang diajukan dengan cara sebagai berikut

Sedangkan formula model analisis yang digunakan adalah sebagai berikut :

\section{Uji F-Statistik}

Secara umum, model populasi dari regresi linier berganda untuk menguji fenomena kuantitatif digunakan permodelan sebagai berikut :

$\mathrm{Y}=\mathrm{a}+\mathrm{b}_{1} \mathrm{X}_{1}+\mathrm{b}_{2} \mathrm{X}_{2}+\mathrm{b}_{3} \mathrm{X}_{3}+\mathrm{e}$

Model persamaan tersebut melalui metode Ordinary Least Squere atau OLS dengan $b_{1}, b_{2}$ dan $b_{3}$

\section{a. Korelasi Linier Berganda}

Untuk mengetahui kesesuaian atau ketepatan hubungan antar variabel dalam persamaan regresi, maka secara umum digunakan pendugaan koefisien determinasi $\left(\mathrm{R}^{2}\right)$ dengan menggunakan model sebagai berikut :
$R^{2}=\frac{b_{1} \sum X_{1} Y+b_{2} \sum X_{2} Y+\ldots \ldots . b_{n} X_{n} Y}{\sum Y^{2}}$

Nilai $\mathrm{R}^{2}$ akan berkisar 0 sampai 1. Apabila nilai $\mathrm{R}^{2}=1$ menunjukkan bahwa $100 \%$ total variasi diterangkan varian persamaan regresi. Sebaliknya apabila nilai $\mathrm{R}^{2}=$ 0 menunjukkan bahwa tidak ada total varians yang diterangkan oleh persamaan regresi.

Seberapa besar nilai $\mathrm{R}^{2}$ baik atau kuat. Menurut Lind (2002) nilai $\mathrm{R}^{2}$ dapat diterangkan dengan menggunakan pedoman yang disajikan dalam tabel 1.3 sebagai berikut :

Tabel 1.3

Pedoman Untuk Memberikan

Interprestasi Koefisien Korelasi

\begin{tabular}{|l|l|}
\hline Interval Koefisien & Tingkat Hubungan \\
\hline $0,80-1,000$ & Sangat Kuat \\
\hline $0,60-0,799$ & Kuat \\
\hline $0,40-0,599$ & Cukup Kuat \\
\hline $0,20-0,399$ & Lemah \\
\hline $0,00-0,199$ & Sangat Lemah \\
\hline
\end{tabular}

b. Pendugaan dari pengujian koefisien regresi berganda

Untuk melihat ketepatan antara nilai dugaan (Y) dengan nilai sebenarnya $(\hat{Y})$, maka dalam mengukur ketidak-akuratan nilai dugaan untuk regresi berganda digunakan rumus sebagai berikut :

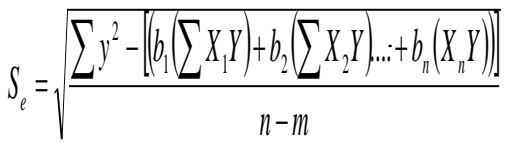


Dimana :

$$
\begin{array}{rlrl}
\mathrm{Se} & =\text { Kesalahan baku regresi } \\
& \text { berganda } \\
\mathrm{n} & =\text { Jumlah observasi } \\
\mathrm{m} & =\text { Jumlah } & \text { konstanta } \\
& \multicolumn{2}{c}{\text { dalam persamaan }} \\
& \text { regresi berganda }
\end{array}
$$

\section{c. Pengujian Hipotesis Regresi Berganda}

Dalam pengujian hipotesa secara serempak dirumuskan hipotesanya yaitu hipotesa nol dan hipotesa alternatif sebagai berikut :

$\mathrm{H}_{\mathrm{o}}: \mathrm{B}_{1}=\mathrm{B}_{2} \ldots \ldots \ldots \ldots . . . \mathrm{B}_{\mathrm{n}}=0$

$\mathrm{H}_{\mathrm{a}}: \mathrm{B}_{1} \neq \mathrm{B}_{2} \ldots \ldots \ldots \ldots . . .=\mathrm{B}_{\mathrm{n}} \neq 0$

Pengujian hipotesa dalam penelitian ini dilakukan untuk melihat apakah variabel $\mathrm{X}_{1}$, $\mathrm{X}_{2}$ dan $\mathrm{X}_{3}$, mampu secara simultan menjelaskan tingkah laku atau keragaman variabel $\mathrm{Y}$ yang masing-masing diamati melalui Uji $-\mathrm{F}$ dengan rumus sebagai berikut

$$
F_{0}=\frac{R^{2} /(k-1)}{\left(1-R^{2}\right) /(n-k-1)}
$$

Berdasarkan formulasi perhitungan di atas, dengan tingkat kesalahan $\alpha=5 \%$. Kemudian dibandingkan dengan $\mathrm{F}$ signifikan dengan menggunakan batasan One Tail Test dapat dilakukan pengujian sebagai berikut :

- Jika F hitung > F signifikan, maka Ho ditolak dan $\mathrm{Ha}$ diterima, yang berarti variabel $\mathrm{X}_{1}, \mathrm{X}_{2}$ ..... Xn secara simultan berpengaruh terhadap variabel Y.

- Jika F hitung < F signifikan , maka Ho diterima dan Ha ditolak, yang berarti variabel $\mathrm{X}_{1}, \mathrm{X}_{2} \quad \ldots \ldots . . \mathrm{Xn}$ secara simultan tidak berpengaruh terhadap variabel Y.

\section{Uji t-Statistik}

\section{a. Regresi Linier (Parsial)}

Secara umum, data hasil pengamatan variabel $\mathrm{Y}$ dipengaruhi oleh variabel $\mathrm{X}$ dalam model populasi dari regresi linier sederhana ialah :

$\mathrm{Y}=\alpha+\beta \mathrm{X}$

Model persamaan tersebut setelah diminimize melalui metode OLS diperoleh model persamaan dugaan sampelnya sebagai berikut :

$$
\hat{Y}=a+b X+e
$$

Keterangan :

Hal yang sama penduga $b$, dan a dapat diselesaikan melalui Metode OLS sebagai berikut:

$$
\begin{aligned}
& b=\frac{\sum X Y-n \overline{X Y}}{\sum X^{2}-n \bar{X}^{2}} \\
& a=\bar{Y}-b \bar{X}
\end{aligned}
$$

\section{b. Korelasi Linier (Parsial)}

Untuk mengukur dan mengamati validitas masingmasing variabel $\mathrm{X}$ terhadap variabel $\mathrm{Y}$ digunakan rumus

$$
p_{x y}=\frac{n \sum X Y-\sum X \sum}{\sqrt{\left[n \sum X^{2}-\left(\sum X\right)^{2} \llbracket n \sum Y^{2}\right.}}
$$

\section{c. Pendugaan dari pengujian} koefisien regresi parsial

Untuk melihat ketepatan dugaan $(\hat{Y})$, berdasarkan nilai $X$ yang diketahui dengan nilai pengamatan (Y), nilai dugaan untuk regresi parsial digunakan rumus sebagai berikut :

1) $S_{e}=\sqrt{\frac{\sum Y^{2}-a \sum Y-b \sum X Y}{n-2}}$

2) Kemudian untuk mencari Koefisien Regresi (Penduga a) Kesalahan bakunya dapat 
diselesaikan sebagai

berikut:

$$
S_{a}=\sqrt{\frac{\sum \mathrm{X}^{2}(S e)}{n \sum \mathrm{X}^{2}-\left(\sum \mathrm{X}\right)^{2}}}
$$

3) Sedangkan Untuk Koefisien

Regresi (Penduga - b)

$$
S_{b}=\sqrt{\frac{S_{e}}{\sum X^{2}-\left(\frac{\sum X}{n}\right)^{2}}}
$$

\section{d. Pengujian Hipotesis Regresi Parsial}

Dalam pengujian hipotesa secara parsial, masing-masing dirumuskan hipotesanya yaitu hipotesa nol dan hipotesa alternatif sebagai berikut :

$\mathrm{H}_{\mathrm{o}}: \mathrm{B}_{1}=0 \mathrm{H}_{\mathrm{a}}: \mathrm{B}_{1} \# 0$

$\mathrm{H}_{\mathrm{o}}: \mathrm{B}_{2}=0 \mathrm{H}_{\mathrm{a}}: \mathrm{B}_{2} \# 0$

Pengujian hipotesa tersebut diamati melalui Uji - T dengan rumus sebagai berikut :

$$
\begin{array}{r}
t_{1}=\frac{\alpha-H_{o}}{S \alpha}, \\
t_{1}=\frac{\beta-H_{o}}{S \beta}
\end{array}
$$

Berdasarkan formulasi perhitungan di atas, dengan tingkat kesalahan $\alpha=5 \%$ kemudian dibandingkan dengan $\mathrm{T}$ signifikan dengan menggunakan batasan One Tail Test dapat dilakukan pengujian sebagai berikut :

- Jika $\mathrm{T}$ hitung $>\mathrm{T}$ signifikan, maka Ho ditolak dan Ha diterima, yang berarti tidak terdapat hubungan yang signifikan antara variabel yang diteliti.

- Jika $\mathrm{T}$ hitung < $\mathrm{T}$ signifikan, maka Ho diterima dan $\mathrm{Ha}$ ditolak, yang berarti terdapat hubungan yang signifikan antara variabel yang diteliti.

1) Untuk menguji dominasi variabel bebas $(\mathrm{X})$ terhadap variabel terikat $(\mathrm{Y})$, maka akan dilakukan dengan cara melihat pada korelasi parsial $\mathrm{R}^{2}$, jika nantinya koefisien korelasi parsial variabel bebas (X) yang paling tinggi akan menunjukkan tingkat hubungan dan pengaruh yang dominan terhadap variabel $\mathrm{Y}$.

2) Untuk menguji kontribusi kemampuan menjelaskan variabel terikat, dapat dilihat dari koefisien determinasi $\left(\mathrm{R}^{2}\right)$, jika nantinya nilai koefisiennya antara $0 \leq 1$, hal ini berarti bahwa $\mathrm{R}^{2}$ yang semakin besar mendekati 1 (satu), merupakan indikator yang menunjukkan semakin kuatnya kemampuan menjelaskan perubahan variabel bebas $\mathrm{X}$ terhadap variansi variabel terikat $Y$.

\section{Hasil dan Pembahasan}

1. Pengujian Asumsi Klasik

Persamaan regresi yang dihasilkan dari perhitungan dengan menggunakan SPSS versi 21 harus diuji kualitasnya dengan menggunakan asumsi klasik sehingga memenuhi syarat Best Linear Unbiased Estimated (BLUE). Beberapa uji asumsi klasik yang harus dipenuhi adalah uji normalitas, autokorelasi, multikolinieritas dan Heteroskedastisitas.

1.1. Uji Normalitas

Pengujian normalitas data digunakan untuk menarik kesimpulan apakah data yang diteliti terdisitribusi secara normal sehingga jika digambarkan akan membentuk kurva normal. Uji normalitas data menggunakan 
Kolmogorov Smirnov dengan hasil dapat dilihat pada tabel berikut.

Tabel 4.49. Hasil perhitungan

Kolmogorov Smirnov

One-Sample Kolmogorov-Smirnov Test

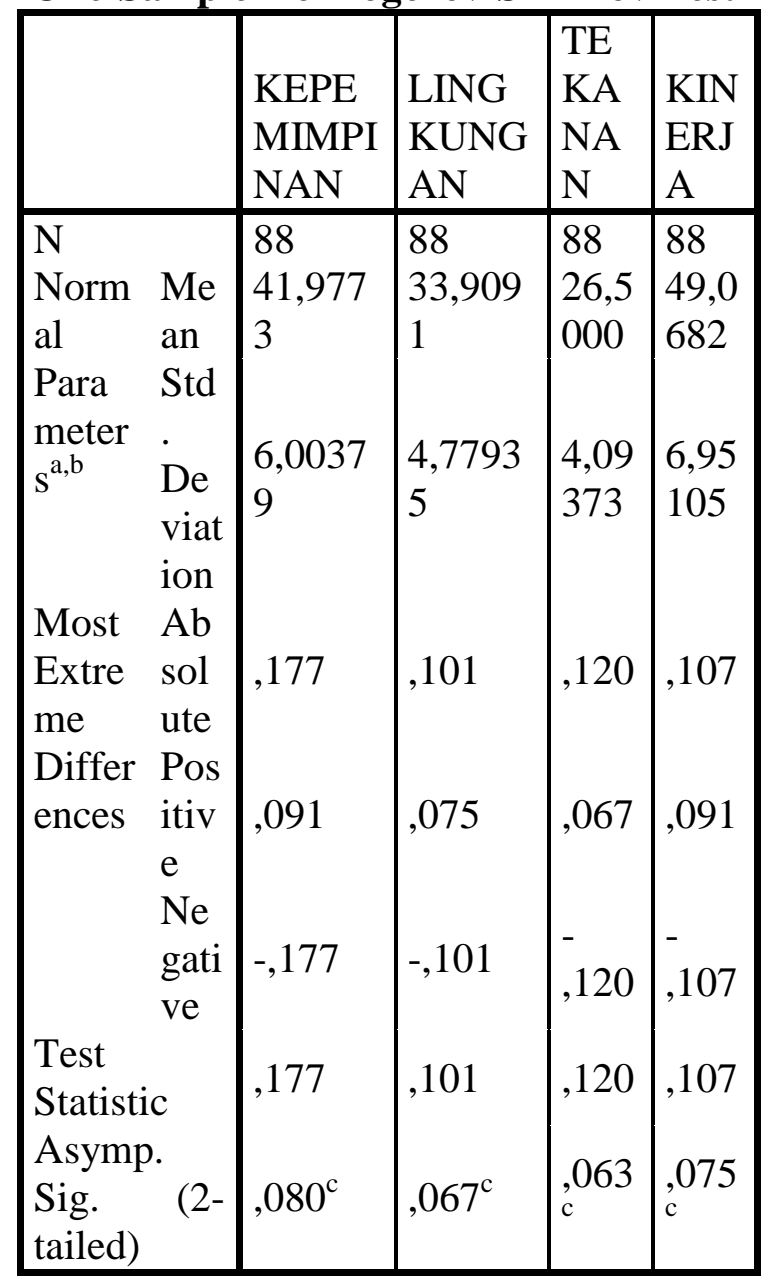

a. Test distribution is Normal.

b. Calculated from data.

c. Lilliefors Significance Correction.

Sumber: data dianalisis

Berdasarkan pada tabel di atas diketahui bahwa data memenuhi asumsi normalitas jika nilai signifikansi memiliki angka yang lebih besar dari 0,05. Data pada tabel di atas menggambarkan bahwa data memiliki angka signifikansi di atas 0,05 sehingga dapat dikatakan bahwa data pada hasil kuisioner memiliki distribusi normal.

\subsection{Uji Autokorelasi Data}

Uji ini meliputi pengujian apakah data pada satu variabel memiliki korelasi yang signifikan atau tidak. Pengujian autokorelasi dapat dilihat dengan menggunakan nilai Durbin Watson sebagai berikut.

Tabel 4.50. Hasil perhitungan Durbin Watson

\section{Model Summary ${ }^{b}$}

\begin{tabular}{|c|c|c|c|c|c|}
\hline $\begin{array}{l}\text { Mod } \\
\text { el }\end{array}$ & $\mathrm{R}$ & \begin{tabular}{|l}
$\mathrm{R}$ \\
$\mathrm{S} q u a r$ \\
$\mathrm{e}$
\end{tabular} & $\begin{array}{l}\text { Adjus } \\
\text { ted R } \\
\text { Squar } \\
\mathrm{e}\end{array}$ & $\begin{array}{l}\text { Std. } \\
\text { Error } \\
\text { of the } \\
\text { Estimat } \\
\mathrm{e}\end{array}$ & $\begin{array}{l}\text { Durbi } \\
\text { n- } \\
\text { Wats } \\
\text { on } \\
\end{array}$ \\
\hline 1 & $\begin{array}{l}, 939 \\
\mathrm{a}\end{array}$ & ,882 & ,878 & $\begin{array}{l}2,4263 \\
5 \\
\end{array}$ & 1,88 \\
\hline
\end{tabular}

a. Predictors: (Constant), TEKANAN, KEPEMIMPINAN, LINGKUNGAN

b. Dependent Variable: KINERJA

Sumber: data dianalisis

Berdasarkan pada tabel di atas nilai Durbin Watson berada pada penerimaan tidak terjadi autokorelasi data.

\subsection{Uji Multikolinieritas Data}

Uji multikolinieritas data merupakan pengujian untuk melihat apakah terjadi korelasi yang tinggi antar variabel independen. Pengujian asumsi ini dilakukan dengan menggunakan nilai VIF. Jika nilai VIF lebih kecil dari 5 maka antar variabel independen tidak terjadi multikolinieritas. Hasil perhitungan VIF dapat dilihat pada tabel berikut.

Tabel 4.51. Hasil perhitungan VIF

\section{Coefficients $^{\text {a }}$}

\begin{tabular}{|ll|l|l|}
\hline \multirow{2}{*}{ Model } & \multicolumn{2}{|l|}{$\begin{array}{l}\text { Collinearity } \\
\text { Statistics }\end{array}$} \\
\cline { 2 - 3 } & $\begin{array}{l}\text { Toler } \\
\text { ance }\end{array}$ & VIF \\
\hline 1 & KEPEMIMPI &, 790 & 1,26 \\
& NAN & 6 \\
& LINGKUNG & & 3,59 \\
AN &, 874 & 3 \\
\hline
\end{tabular}




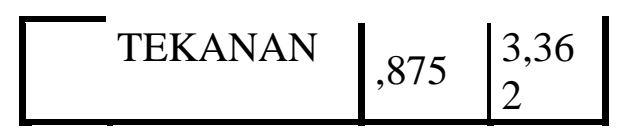

a. Dependent Variable:

KINERJA

Sumber: data dianalisis

Berdasarkan pada tabel di atas diketahui bahwa nilai VIF lebih kecil dari 5 sehingga dapat dikatakan bahwa variabel independen tidak saling berkorelasi.

\subsection{Pengaruh kepemimpinan, lingkungan} kerja dan tekanan pekerjaan secara simultan terhadap kinerja

Analisis ini untuk menjawab apakah hipotesis pertama dapat diterima. Analisis ini menggunakan persamaan regresi linear berganda. Pehitungan koefisien regresi untuk membentuk model regresi dilakukan dengan menggunakan SPSS versi 21. Hasil analisis data dapat dilihat pada tabel berikut.

\section{Tabel 4.52. Hasil analisis data persamaan regresi berganda}

\begin{tabular}{|c|c|c|c|c|c|}
\hline \multicolumn{6}{|c|}{ Coefficients $^{a}$} \\
\hline \multirow[b]{2}{*}{ Model } & \multicolumn{2}{|c|}{$\begin{array}{l}\text { Unstandardi } \\
\text { zed } \\
\text { Coefficients }\end{array}$} & \multirow{2}{*}{$\begin{array}{l}\text { Stand } \\
\text { ardiz } \\
\text { ed } \\
\text { Coeff } \\
\text { icient } \\
\text { s } \\
\text { Beta }\end{array}$} & \multirow[b]{2}{*}{$\mathrm{t}$} & \multirow[b]{2}{*}{$\begin{array}{l}\mathrm{Si} \\
\mathrm{g} .\end{array}$} \\
\hline & B & $\begin{array}{l}\text { Std. } \\
\text { Error }\end{array}$ & & & \\
\hline $\begin{array}{l}1 \text { (Consta } \\
n t)\end{array}$ & $\begin{array}{l}- \\
1,62 \\
1\end{array}$ & 2,504 & & $\begin{array}{l}- \\
, 6 \\
47\end{array}$ & $\begin{array}{l}, 51 \\
9\end{array}$ \\
\hline KEPEM & & & & 3 & 00 \\
\hline $\begin{array}{l}\text { IMPINA } \\
\mathrm{N}\end{array}$ &, 192 &, 049 & , 166 & $\begin{array}{l}94 \\
0\end{array}$ & $\begin{array}{l}, 00 \\
0\end{array}$ \\
\hline LINGK & & & & 1 , & \\
\hline $\begin{array}{l}\text { UNGA } \\
\mathrm{N}\end{array}$ &, 284 & ,201 & , 195 & $\begin{array}{l}41 \\
4\end{array}$ & $\begin{array}{l}, 10 \\
1\end{array}$ \\
\hline $\begin{array}{l}\text { TEKAN } \\
\text { AN }\end{array}$ & $\begin{array}{l}1,24 \\
6\end{array}$ & ,232 & ,734 & $\begin{array}{l}5, \\
36 \\
2\end{array}$ & $\begin{array}{l}, 00 \\
0\end{array}$ \\
\hline
\end{tabular}

a. Dependent Variable: KINERJA

Sumber: data dianalisis
Untuk membentuk persamaan regresi berganda maka perlu diketahui besarnya kofisien masing-masing variabel dan nilai dari konstanta a. Berdasarkan pada tabel di atas diketahui bahwa persamaan regresi berganda dapat dibuat sebagai berikut: $\mathrm{Y}=-1.621+0,192 \mathrm{X}_{1}+0,284 \mathrm{X}_{2}+1,246 \mathrm{X}_{3}$ dalam hal ini

$\mathrm{Y}=$ kinerja

$a=-1,621$

$\mathrm{b}_{1}=0,192$

$\mathrm{b}_{2}=0,284$

b3 $=1,246$

$\mathrm{X}_{1}=$ kepemimpinan

$\mathrm{X}_{2}=$ lingkungan kerja

$\mathrm{X}_{3}=$ tekanan pekerjaan

$\mathrm{Y}=$ kinerja

Nilai koefisien $b_{1}$ dan $b_{3}$ bernilai positif artinya semakin besar kepemimpinan dan tekanan pekerjaan maka kinerja karyawan juga akan semakin besar. Apakah ketiga variabel tersebut secara simultan berpengaruh terhadap kinerja karyawan maka perlu dilakukan pengujian terhadap $\mathrm{F}$ hitung dengan hasil sebagai berikut.

Tabel 4.53. Hasil perhitungan $F$ pada persamaan simultan

\begin{tabular}{|c|c|c|c|c|c|}
\hline \multicolumn{6}{|c|}{ ANOVA $^{\mathbf{a}^{\mathbf{t}}}$} \\
\hline Model & $\begin{array}{l}\text { Sum of } \\
\text { Square } \\
\text { s }\end{array}$ & Df & \begin{tabular}{|l} 
Mea \\
n \\
Squa \\
re
\end{tabular} & $\mathrm{F}$ & Sig \\
\hline $\begin{array}{c}1 \text { Regre } \\
\text { ssion }\end{array}$ & $\begin{array}{l}3709,0 \\
70\end{array}$ & 3 & $\begin{array}{l}1236 \\
, 357\end{array}$ & $\begin{array}{l}21, \\
00 \\
0\end{array}$ & $\begin{array}{l}, 00 \\
0^{\mathrm{b}}\end{array}$ \\
\hline $\begin{array}{l}\text { Resid } \\
\text { ual }\end{array}$ & $\begin{array}{l}494,52 \\
1\end{array}$ & 84 & \begin{tabular}{|l}
5,88 \\
7
\end{tabular} & & \\
\hline Total & $\begin{array}{l}4203,5 \\
91\end{array}$ & 87 & & & \\
\hline
\end{tabular}

a. Dependent Variable: KINERJA

b. Predictors: (Constant), TEKANAN, KEPEMIMPINAN, LINGKUNGAN Sumber: data dianalisis

Berdasarkan pada tabel di atas diketahui nilai $\mathrm{F}$ hitung sebesar 21,009 dengan tingkat signifikansi sebesar 0,000 maka dapat disimpulkan bahwa kepemimpinan, 
lingkungan kerja dan tekanan pekerjaan berpengaruh simultan terhadap kinerja karyawan.

Besarnya pengaruh variabel kepemimpinan, lingkungan kerja dan tekanan pekerjaan terhadap kinerja karyawan dapat dilakukan perhitungan dengan menggunakan $r$ kuadrat dengan hasil sebagai berikut.

\section{Tabel 4.54. Hasil perhitungan $r$ kuadrat persamaan simultan Model Summary ${ }^{b}$}

\begin{tabular}{|c|c|c|c|c|c|}
\hline Model & $\mathrm{R}$ & R Square & $\begin{array}{l}\text { Adjusted } \\
\text { R Square }\end{array}$ & $\begin{array}{l}\text { Std. Error= } 0 f, 0 \text { the } \\
\text { Estimate Nilai koef }\end{array}$ & Sierbjin-Katssp \\
\hline 1 &, $939^{\mathrm{a}}$ &, 882 & ,878 & 2,42635 berarti sen & hakin 8 esar kepemimpina \\
\hline
\end{tabular}

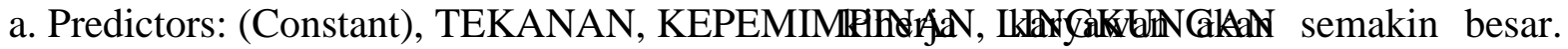

b. Dependent Variable: KINERJA

Sumber: data dianalisis

Berdasarkan pada data di atas diketahui bahwa nilai r kuadrat sebesar 0,882 . Hal ini berarti variabel kepemimpinan dan lingkungan kerja berpengaruh terhadap lingkungan kerja karyawan sebesar 88,2 $\%$ sedangkan sisanya dipengaruhi oleh variabel lain yang tidak dimasukkan kedalam model persamaan.

2.2. Analisis pengaruh kepemimpinan secara parsial terhadap kinerja karyawan

Model untuk menggambarkan pengaruh kepemimpinan terhadap kinerja secara parsial dapat digambarkan dari hasil pehitungan persamaan dari SPSS seperti terlihat pada tabel berikut.

\section{Tabel 4.55. Hasil perhitungan} koefisien model parsial 1

\section{Coefficients $^{\mathrm{a}}$}

\begin{tabular}{|c|c|c|c|c|c|}
\hline & & $\begin{array}{l}\text { anda } \\
\text { d } \\
\text { ficie }\end{array}$ & $\begin{array}{l}\text { Stand } \\
\text { ardize } \\
\text { d } \\
\text { Coeff } \\
\text { icient } \\
\text { s } \\
\end{array}$ & & \\
\hline Model & B & \begin{tabular}{|l} 
Std \\
Err \\
or
\end{tabular} & Beta & $\mathrm{T}$ & Sig. \\
\hline
\end{tabular}

\begin{tabular}{|l|l|l|l|l|l|}
\hline 1 (Consta & 40,0 & 5,2 & & 7,7 &, 000 \\
nt) & 98 & 02 & & 07 & \\
KEPE & &, 12 & & 1,7 & \\
MIMPI &, 214 & 3 &, 185 & 42 &, 085 \\
NAN & & 3 & & & \\
\hline
\end{tabular}

a. Dependent Variable: KINERJA

Sumber: data dianalisis

Persamaan parsial dapat dibuat sebagai berikut

$\mathrm{Y}=40,098+0,214 \mathrm{X}_{1}$

dalam hal ini

Y=kinerja
Apakah variabel kepemimpinan

berpengaruh terhadap kinerja maka dilakukan pengujian dengan menggunakan t sebagai berikut.

Tabel 4.56. Hasil pengujian persamaan parsial pertama

\section{Coefficients $^{\mathrm{a}}$}

\begin{tabular}{|c|c|c|c|c|c|}
\hline \multirow[b]{2}{*}{ Model } & \multicolumn{2}{|c|}{$\begin{array}{l}\text { Unstand } \\
\text { ardized } \\
\text { Coeffici } \\
\text { ents }\end{array}$} & $\begin{array}{l}\text { Stand } \\
\text { ardize } \\
\text { d } \\
\text { Coeffi } \\
\text { cients }\end{array}$ & \multirow[b]{2}{*}{$\mathrm{t}$} & \multirow[b]{2}{*}{$\begin{array}{l}\mathrm{Si} \\
\mathrm{g} .\end{array}$} \\
\hline & B & $\begin{array}{l}\text { Std. } \\
\text { Err } \\
\text { or }\end{array}$ & Beta & & \\
\hline $\begin{array}{l}1 \text { (Constan } \\
\text { t) }\end{array}$ & $\begin{array}{l}40 \\
09 \\
8\end{array}$ & $\begin{array}{l}5,2 \\
02\end{array}$ & & $\begin{array}{l}7 \\
70 \\
7\end{array}$ & $\begin{array}{l}, 00 \\
0\end{array}$ \\
\hline $\begin{array}{l}\text { KEPEMI } \\
\text { MPINA } \\
\mathrm{N}\end{array}$ & $\begin{array}{l}, 21 \\
4\end{array}$ & $\begin{array}{l}12 \\
3\end{array}$ &, 185 & $\begin{array}{l}3 \\
74 \\
2\end{array}$ & $\begin{array}{l}, 00 \\
5\end{array}$ \\
\hline
\end{tabular}

a. Dependent Variable: KINERJA

Sumber: data dianalisis

Berdasarkan pada tabel di atas diketahui bahwa signifikansi t hitung 3,742 dan signifikansi kurang dari $5 \%$ dan hal ini menunjukkan bahwa variabel kepemimpinan berpengaruh terhadap kinerja secara parsial.

Besarnya pengaruh variabel kepemimpinan terhadap kinerja dapat 
dihitung dengan menggunakan $\mathrm{r}$ kuadrat dengan hasil sebagai berikut.

Tabel 4.46. Hasil $r$ kuadrat persamaan parsial pertama

\section{Model Summary}

\begin{tabular}{|c|c|c|c|c|}
\hline $\begin{array}{l}\text { Mode } \\
1\end{array}$ & $\mathrm{R}$ & $\begin{array}{l}\mathrm{R} \\
\text { Squar } \\
\mathrm{e}\end{array}$ & $\begin{array}{l}\text { Adjuste } \\
\text { d R R } \\
\text { Square }\end{array}$ & $\begin{array}{l}\text { Std. } \\
\text { Error of } \\
\text { the } \\
\text { Estimat } \\
\text { e }\end{array}$ \\
\hline 1 & , 185 &, 34 &, 023 & 6,87123 \\
\hline
\end{tabular}

a. Predictors:

KEPEMIMPINAN

Sumber: data dianalisi

Berdasarkan pada tabel di atas diketahui bahwa nilai kuadrat sebesar 0,340 artinya variabel kepemimpinan berpengaruht erhadap variabel lingkungan kerja sebesar 34,0 \% sedangkan sisanya dipengaruhi variabel lain yang tidak diteliti

2.3. Pengaruh lingkungan kerja secara parsial terhadap kinerja karyawan Model persamaan regresi sederhana kedua dapat digambarkan sebagai berikut.

Tabel 4.47. Model regresi kedua Coefficients $^{\mathrm{a}}$

\begin{tabular}{|c|c|c|c|c|c|}
\hline \multirow[b]{2}{*}{ Model } & \multicolumn{2}{|c|}{$\begin{array}{l}\text { Unstanda } \\
\text { rdized } \\
\text { Coefficie } \\
\text { nts } \\
\end{array}$} & \begin{tabular}{|l} 
Standar \\
dized \\
Coeffic \\
ients \\
\end{tabular} & & \\
\hline & B & $\begin{array}{l}\text { Std. } \\
\text { Err } \\
\text { or }\end{array}$ & Beta & $\mathrm{t}$ & $\begin{array}{l}\mathrm{Si} \\
\text { g. }\end{array}$ \\
\hline $\begin{array}{l}1 \text { (Constant } \\
\text { ) }\end{array}$ & $\begin{array}{l}3,9 \\
27\end{array}$ & $\begin{array}{l}2,1 \\
63\end{array}$ & & $\begin{array}{l}1,8 \\
16\end{array}$ & $\begin{array}{l}, 0 \\
7\end{array}$ \\
\hline $\begin{array}{l}\text { LINGKU } \\
\text { NGAN }\end{array}$ & $\begin{array}{l}1,3 \\
31\end{array}$ & $\begin{array}{l}, 06 \\
3\end{array}$ & ,915 & $\begin{array}{l}21 \\
078\end{array}$ & $\begin{array}{l}, 0 \\
0 \\
0\end{array}$ \\
\hline
\end{tabular}

a. Dependent Variable: KINERJA

Sumber: data dianalisis

Model regresi kedua dapat ditulis sebagai berikut
$\mathrm{Y}=3,927+1,331 \mathrm{X}_{2}$

dalam hal ini

$\mathrm{Y}=$ kinerja

$\mathrm{X}_{2}=$ lingkungan kerja

$\mathrm{a}=$ konstanta

$\mathrm{b}_{2}=$ koefisien variabel $\mathrm{X}_{2}$

Berdasarkan pada tabel di atas koeisien variabel lingkungan kerja bertanda positif hal ini berarti semakin tinggi lingkungan kerja maka kinerja karyawan semakin tinggi juga.

Apakah variabel lingkungan kerja berpengaruh terhadap kinerja secara parsial maka dilakukan analisis terhadap $\mathrm{t}$ dengan hasil sebagai berikut.

Tabel 4.48. Nilai $t$ hitung persamaan regresi kedua

Coefficients $^{\mathrm{a}}$

\begin{tabular}{|c|c|c|c|c|c|}
\hline \multirow[b]{2}{*}{ Model } & \multicolumn{2}{|c|}{$\begin{array}{l}\text { Unstandardi } \\
\text { zed } \\
\text { Coefficients }\end{array}$} & $\begin{array}{l}\text { Standa } \\
\text { rdized } \\
\text { Coeffi } \\
\text { cients } \\
\end{array}$ & & \\
\hline & B & $\begin{array}{l}\text { Std. } \\
\text { Error }\end{array}$ & Beta & $t$ & $\begin{array}{l}\mathrm{Si} \\
\mathrm{g} .\end{array}$ \\
\hline $\begin{array}{ll}1 & \text { (Const } \\
& \text { ant) }\end{array}$ & $\begin{array}{l}3,9 \\
27\end{array}$ & 2,163 & & $\begin{array}{l}1,8 \\
16\end{array}$ & $\begin{array}{l}0 \\
73\end{array}$ \\
\hline $\begin{array}{l}\text { LING } \\
\text { KUN } \\
\text { GAN }\end{array}$ & $\begin{array}{l}1,3 \\
31\end{array}$ &, 063 & ,915 & $\begin{array}{l}21 \\
078\end{array}$ & $\begin{array}{l}, 0 \\
00\end{array}$ \\
\hline
\end{tabular}

a. Dependent Variable: KINERJA

Sumber: data dianalisis

Berdasarkan pada tabel di atas diketahui nilai hitung 21,078 dengan signifikansi sebesar 0,00 atau kurang dari $5 \%$. Hal ini berarti bahwa variabel lingkungan kerja berpengaruh terhadap kinerja secara parsial.

Besarnya pengaruh lingkungan kerja terhadap kinerja dapat dilihat dengan menggunakan nilai $r$ kuadrat dengan hasil sebagai berikut.

Tabel 4.49. Nilai $r$ kuadrat persamaan parsial pertama

Model Summary

\begin{tabular}{|c|c|c|c|c|}
\hline $\mathrm{M}$ & $\mathrm{R}$ & \begin{tabular}{|l}
$\mathrm{R}$ \\
Squar \\
$\mathrm{e}$
\end{tabular} & $\begin{array}{l}\text { Adjust } \\
\text { ed R } \\
\text { Square }\end{array}$ & $\begin{array}{l}\text { Std. Error } \\
\text { of the } \\
\text { Estimate }\end{array}$ \\
\hline
\end{tabular}




\begin{tabular}{|l|l|l|l|l|}
\hline 1 & $\begin{array}{l}, 915 \\
\mathrm{a}^{-}\end{array}$ &, 838 &, 836 & 2,81550 \\
\hline \multicolumn{4}{|c|}{ Predictors: } & (Constant),
\end{tabular}

\section{LINGKUNGAN}

Sumber: data dianalisis

Berdasarkan pada di atas diketahui bahwa nilai $r$ kuadrat sebesar 0,838. Hal ini berarti bahwa pengaruh variabel lingkungan kerja terhadap kinerja karyawan adalah sebesar $83,8 \%$.

2.4. Pengaruh Tekanan pekerjaan secara parsial terhadap kinerja karyawan

Model persamaan regresi sederhana kedua dapat digambarkan sebagai berikut.

Tabel 4.50. Model regresi kedua Coefficients $^{\mathrm{a}}$

\begin{tabular}{|c|c|c|c|c|c|}
\hline \multirow[b]{2}{*}{ Model } & \multicolumn{2}{|c|}{$\begin{array}{l}\text { Unstanda } \\
\text { rdized } \\
\text { Coefficie } \\
\text { nts }\end{array}$} & $\begin{array}{l}\text { Stand } \\
\text { ardize } \\
\text { d } \\
\text { Coeff } \\
\text { icient } \\
\text { s }\end{array}$ & \multirow[b]{2}{*}{$\mathrm{t}$} & \multirow[b]{2}{*}{ Sig. } \\
\hline & $\mathrm{B}$ & \begin{tabular}{|l} 
Std. \\
Err \\
or \\
\end{tabular} & Beta & & \\
\hline $\begin{array}{ll}1 & \text { (Cons } \\
& \operatorname{tant} t)\end{array}$ & $\begin{array}{l}7,7 \\
73\end{array}$ & $\begin{array}{l}1,9 \\
50\end{array}$ & & 3,987 &, 000 \\
\hline $\begin{array}{l}\text { TEK } \\
\text { ANA } \\
\mathrm{N}\end{array}$ & $\begin{array}{l}1,5 \\
58\end{array}$ & $\begin{array}{l}, 07 \\
3\end{array}$ & ,918 & $\begin{array}{l}21,42 \\
8\end{array}$ & , 000 \\
\hline
\end{tabular}

a. Dependent Variable: KINERJA

sumber: data dianalisis

Model regresi kedua dapat ditulis sebagai berikut

$\mathrm{Y}=7,773+1,558 \mathrm{X}_{3}$

dalam hal ini

$\mathrm{Y}=$ kinerja

$\mathrm{X}_{3}=$ tekanan pekerjaan

$\mathrm{a}=$ konstanta

$\mathrm{b}_{3}=$ koefisien variabel $\mathrm{X}_{3}$

Berdasarkan pada tabel di atas koeisien variabel tekanan pekerjaan bertanda positif hal ini berarti semakin tinggi tekanan pekerjaan maka kinerja karyawan semakin tinggi juga.

Apakah variabel tekanan pekerjaan berpengaruh terhadap kinerja secara parsial maka dilakukan analisis terhadap $\mathrm{t}$ dengan hasil sebagai berikut.
Tabel 4.51. Nilai $t$ hitung persamaan regresi kedua

\section{Coefficients $^{\mathrm{a}}$}

\begin{tabular}{|c|c|c|c|c|c|}
\hline \multirow[b]{2}{*}{ Model } & \multicolumn{2}{|c|}{$\begin{array}{l}\text { Unstanda } \\
\text { rdized } \\
\text { Coefficie } \\
\text { nts }\end{array}$} & \multirow{2}{*}{\begin{tabular}{|l} 
Stand \\
ardiz \\
ed \\
Coeff \\
icient \\
s \\
\\
Beta \\
\end{tabular}} & \multirow[b]{2}{*}{$\mathrm{t}$} & \multirow[b]{2}{*}{ Sig. } \\
\hline & B & $\begin{array}{l}\text { Std. } \\
\text { Err } \\
\text { or }\end{array}$ & & & \\
\hline $\begin{array}{ll}1 & \text { (Con } \\
& \text { stant })\end{array}$ & $\begin{array}{l}7,7 \\
73\end{array}$ & $\begin{array}{l}1,9 \\
50\end{array}$ & & 3,987 & ,000 \\
\hline $\begin{array}{l}\text { TEK } \\
\text { ANA } \\
\mathrm{N}\end{array}$ & $\begin{array}{l}1,5 \\
58\end{array}$ & $\begin{array}{l}, 07 \\
3\end{array}$ & ,918 & $\begin{array}{l}21,42 \\
8\end{array}$ & ,000 \\
\hline
\end{tabular}

a. Dependent Variable: KINERJA

Sumber: data dianalisis

Berdasarkan pada tabel di atas diketahui nilai hitung 21,428 dengan signifikansi sebesar 0,00 atau kurang dari $5 \%$. Hal ini berarti bahwa variabel tekanan pekerjaan berpengaruh terhadap kinerja secara parsial.

Besarnya pengaruh tekanan pekerjaan terhadap kinerja dapat dilihat dengan menggunakan nilai $r$ kuadrat dengan hasil sebagai berikut.

\section{Tabel 4.52. Nilai $r$ kuadra dari model persamaan parsial kedua}

Model Summary

\begin{tabular}{|c|c|c|c|c|}
\hline $\begin{array}{l}\text { Mode } \\
1\end{array}$ & $\mathrm{R}$ & $\begin{array}{l}\text { R } \\
\text { Squar } \\
\text { e }\end{array}$ & $\begin{array}{l}\text { Adjust } \\
\text { ed R } \\
\text { Square }\end{array}$ & \begin{tabular}{|l} 
Std. \\
Error \\
of the \\
Estima \\
te
\end{tabular} \\
\hline 1 & ,918 & ,842 &, 840 & $\begin{array}{l}2,7768 \\
5\end{array}$ \\
\hline
\end{tabular}

a. Predictors: (Constant), TEKANAN

Sumber: data dianalisis

Berdasarkan pada tabel di atas dapat diketahui bahwa nilai $r$ kuadrat sebesar 0,842 artinya variabel lingkungan 
kerja mempengaruhi lingkungan kerja sebesar 84,2 \% sedangkan sisanya dipengaruhi oleh variable lain yang tidak dimasukan pada model.

\section{Kesimpulan}

1. variabel kepemimpinan berpengaruh terhadap kinerja karyawan sebesar 0,340. Artinya variabel kepemimpinan secara parsial berpengaruh terhadap kinerja karyawan sebesar 34\%.

2. Variabel lingkungan kerja berpengaruh terhadap kinerja karyawan sebesar 0,838. Artinya variabel lingkungan kerja berpengaruh secara signifikan terhadap kinerja karyawan sebesar $83,8 \%$.

3. Variabel tekanan pekerjaan berpengaruh terhadap kinerja karyawan sebesar 0,842. Artinya variabel tekanan pekerjaan berpengaruh secara signifikan terhadap kinerja karyawan sebesar $84,2 \%$.

4. Variabel kepemimpinan, lingkungan dan tekanan pekerjaan secara simultan berpengaruh terhadap kinerja karyawan sebesar 0,882. Artinya bahwa kepemimpinan, lingkungan dan tekanan pekerjaan berpengaruh secara simultan terhadap kinerja karyawan PT. Menara Hutama Cibitung sebesar $88,2 \%$ sedangkan sisanya $12,8 \%$ dipengaruhi oleh faktor lain yang tidak termasuk dalam lingkup penelitian ini.

\section{DAFTAR PUSTAKA}

Azwar, Saifuddin. 2004. Sikap Manusia : Teori dan Pengukurannya. Yogyakarta, Liberty.

Baron, Robert, and Jerald Greenberg, 2003, Organizational Behavior, $6^{\text {th }}$ Edition, Prentice Hall, New Jersey
Bemardin, H. John, 2003, Human Resources Management: An Experiential Approach $3^{\text {rd }}$ edition, McGraw-Hill/Irwin, New York

Boediono, B. 2003. Pelayanan Prima Perpajakan. Jakarta, Rineka Cipta Bambang

Dessler Gary, Manajemen Sumber Daya Manusia, PT. Indeks Kelompok Gramedia, Jakarta, 2005

Dermawan Wibisono, Manajemen Prestasi Kerja (Konsep Desain, dan Teknik Meningkatkan Daya Saing Perusahaan, Erlangga, Jakarta, 2006

Dessler, Gary, 2000, Human Resources Management, $8^{\text {th }}$ Edition, Prentice hall, International Inc.

Darwish A. Yousef, 2000. "Organizational Commitment : A Mediator of Relationship of Leadership Behavior with Job Satisfaction and Performance in a Non - Western Country. Journal of Managerial Psychology. 15.1

Davis, Keith and John W. Stroom, 1997, Organizational behavior, Human Behavior at Work, $10^{\text {th }}$ Edition, International Edition, McGraw-Hill, New York.

Gibson, James L., John M.Ivancevich, and James H.Donnelly, 1996, Organization Behavior-StructureProcess, $7^{\text {th }}$ Edition, Erwin homewood, Boston.

Hadari Nawawi. 2003. Manajemen Sumber Daya Manusia Untuk Bisnis yang Competitif, Gajah Mada University Press, Yogyakarta.

Hamid. 2006. Motivasi Kerja Karyawan, Armico, Bandung. 